\title{
ESPIRITUALIDAD Y MEMORIA EN LOS PÚLPITOS. LA ORDEN TRINITARIA Y EL CICLO DE SERMONES EN LAS EXEQUIAS DEL CONDE DE OLIVARES (1624)
}

\author{
SPIRITUALITY AND MEMORY IN THE PULPITS. THE TRINITARIAN \\ ORDER AND THE SERIES OF SERMONS IN THE FUNERAL OF THE \\ COUNT OF OLIVARES (1624)
}

Fernando Negredo del CERRO

Instituto de Estudios Hispánicos en la Modernidad (IEHM)

\section{RESUMEN}

Las relaciones entre nobleza y estamento eclesiástico son un elemento fundamental para entender el funcionamiento de las sociedades de Antiguo Régimen y la reproducción de élites. En el presente artículo abordamos una fuente, en gran medida desconocida, para profundizar en ambos aspectos: un conjunto de sermones predicados el mismo día por miembros de una sola orden, la de la Santísima Trinidad, y con idéntico motivo, celebrar las exequias fúnebres del conde de Olivares, padre del famoso valido de Felipe IV. A través de la contextualización amplia de estos escritos intentamos establecer una serie de conclusiones que valoren en su justa medida las numerosas facetas terrenales que subyacen a una muestra de espiritualidad tan habitual como fue la predicación por las almas de los difuntos.

Palabras clave: Conde-Duque de Olivares; Predicación; Sermones funerales; Luis de Córdoba Ronquillo; Andalucía. 


\section{ABSTRACT}

The relations between the nobility and the ecclesiastical establishment are a fundamental element to understand the functioning of the Ancien Régime societies and the reproduction of elites. In this article we present a source, largely unknown, to delve into both aspects: a set of sermons preached on the same day by members of a single order, the Holy Trinity, and with the same reason, celebrate the funeral services of the Count of Olivares, Philip IV's famous favorite's father. Through the broad contextualization of these writings, we try to establish a series of conclusions in order to show the many earthly facets that underlie a sample of spirituality as common as preaching for the souls of the deceased.

Keywords: Count-Duke of Olivares; Preaching; funeral sermons; Luis de Córdoba Ronquillo, Andalusia.

\section{INTRODUCCIÓN}

Las relaciones entre aristocracia y clero regular son, hoy en día, un terreno bastante ignoto en lo que a aportaciones historiográficas rigurosas se refiere. Las implicaciones sociales, económicas, políticas y culturales de tal filiación siguen quedando en gran medida en la sombra, a pesar de meritorios pero escasos trabajos al respecto ${ }^{1}$. La cuestión no es baladí pues su estudio nos ayudaría a entender bastante mejor los mecanismos de control social y reproducción de elites, aspectos fundamentales para comprender el devenir de la sociedad castellana en el Antiguo Régimen y, especialmente, a lo largo del siglo XVII, periodo en el que hemos centrado nuestras pesquisas. Las razones de esta carencia no nos son dadas explicitarlas aquí, pero mucho tienen que ver, en primer lugar, con las fuentes habitualmente utilizadas para acercarse al mundo eclesiástico y, en segundo, con unos enfoques apriorísticos que dan en numerosas ocasiones por sentado una autonomía social del estamento eclesiástico al situarlo en un plano diferente, cuando no superior, al del resto de sus contemporáneos. En esta visión,

1 Citemos solamente dos, bastante recientes e interesantes en su enfoque: Ángela Atienza López y José Luis Beltrán Moya, "Religiosos y religiosas. Lazos e intereses de familia en el seno del clero regular en el mundo hispánico de la Edad Moderna" en Familias en el Viejo y en el Nuevo Mundo, ed. por Ofelia Rey Castelao y Pablo Cowen (La Plata: Universidad Nacional, 2017), 214-243 y Raúl Molina Recio, "Iglesia y economía: la inversión nobiliaria en el mundo eclesiástico y su retorno económico. El ejemplo de los Fernández de Córdoba", en Poder, sociedad, religión y tolerancia en el mundo hispánico, de Fernando el Católico al siglo XVIII, ed. por Eliseo Serrano Martín y Jesús Gascón Pérez (Zaragoza: Institución Fernando el Católico, 2018), 1529-1547. 
la espiritualidad se enfoca como una actitud meramente trascendente despojándola de toda inmanencia y desgajándola del contexto en que se generó. Se ofrece así una lectura en cierto modo presentista del hecho religioso que permite su rápida vinculación con las vivencias contemporáneas, pero a costa de eliminar su idiosincrasia. Ante esto, nuestra propuesta incidirá en imbricar una muestra de espiritualidad en su realidad barroca para poder desentrañar con objetividad los mensajes que a través de ella se articularon. Por supuesto no aspiramos a establecer una interpretación única de los textos rescatados pero sí que nuestro empeño va encaminado a decodificarlas basándonos en el horizonte cultural que adivinamos para los hombres de la decimoséptima centuria, no en el nuestro, aunque sabemos de la imposibilidad de obviar nuestros propios condicionantes ${ }^{2}$. De hecho, en un espacio tan reducido como el que este artículo nos ofrece, no podremos descender apenas a la interpretación de los textos y nos quedaremos, sobre todo, en los contextos.

En consonancia con lo expuesto, a continuación proponemos una reflexión centrada en una fuente que nos parece de gran interés por una serie de razones que expondremos un poco más abajo. En esta ocasión abordamos el análisis de un ciclo fúnebre con características singulares. No presentamos, por tanto, ni el estudio de un sermón en particular, ni de un autor en concreto, sino que reflexionaremos sobre el horizonte político, espiritual y personal de un conjunto de textos que recogen diferentes prédicas coincidentes en el tiempo y en el tema.

\section{LA FUENTE Y SU CONTEXTO}

Los textos sobre los que trabajaremos se corresponden con doce sermones predicados todos el mismo día (3 de noviembre de 1624) por una docena de frailes trinitarios calzados - cada uno en una iglesia conventual diferente- $-\mathrm{y}$ compilados por el provincial y vicario general de la provincia de Andalucía de dicha orden, fray Luis de Córdoba Ronquillo, de quien además, muy posiblemente, surgió la idea ${ }^{3}$.Es, por tanto una colección de sermones cuyos autores y

2 Referenciar bibliográficamente estas aseveraciones nos llevaría mucho más espacio del que disponemos. De Lotman a Skinner, de Ricour a F. Rodríguez de la Flor, son numerosos los autores que han mostrado las posibles lecturas y relecturas de los textos artísticos $-\mathrm{y}$ los de la oratoria sagrada lo son- en el Barroco. Y, a pesar de que en el ámbito de la deconstrucción se niegue la posibilidad de reconstruir los contextos, creemos que el historiador debe hacer todo lo posible por conocerlos en la línea de lo que expone Manuel Asensi Pérez en el primer capítulo de su Crítica y sabotaje, (Barcelona: Anthropos, 2011).

3 Luis de Córdoba Ronquillo (rec.) Sermones fúnebres predicados dominica infraoctava de todos santos de 1624 años en la provincia del Andalucía del orden de la Santísima Trinidad de Redentores en 
lugares de predicación cubren los más importantes conventos de esta provincia mendicante 4 como el propio editor reflejaba en el prólogo donde nos indica que, en realidad, el ciclo debió cubrir todas las casas de la provincia:

"Yo, en su nombre, dedico a V. Exc a . este libro de doce oraciones fúnebres, que la Provincia, entre otras, predicó en sus mayores casas, domingo 3 de Noviembre infra octavo de los Santos; que siendo los Conventos y oradores más, ya por la grandeza de las ciudades, ya por la mejora de las fundaciones, ya, también, por la opinión de los sujetos, entregué para la estampa solos estos doce elogios..."

Y podemos apreciar en el siguiente cuadro:

\begin{tabular}{|c|c|c|}
\hline CIUDAD & PREDICADOR & PÁGINAS \\
\hline Sevilla & Fr. Luis de Córdoba Ronquillo & $1-40$ \\
\hline Córdoba & Fr. Juan Ortiz & $41-67$ \\
\hline Granada & Fr. Lope Enríquez & $68-87$ \\
\hline Úbeda & Fr. Miguel Ruiz & $89-127$ \\
\hline Málaga & Fr. Alonso de Contreras & $129-146$ \\
\hline Jaén & Fr. Juan Redondo & $147-183$ \\
\hline Badajoz & Fr. Andrés Martínez & $185-211$ \\
\hline Murcia & Fr. Diego de Haro Manrique & $215-242$ \\
\hline Andújar & Fr. José de Valencia & $243-281$ \\
\hline Jerez de la Frontera & Fr. Rodrigo de Castro & $283-305$ \\
\hline Baeza & Fr. Juan de Aguilar & $307-333$ \\
\hline Marbella & Fr. Juan de Vallés & $335-353$ \\
\hline
\end{tabular}

las honras de los excelentísimos señores don Enrique de Guzmán, conde de Olivares, virrey que fue de Sicilia y Nápoles, embajador que fue en Roma y del consejo de Estado y Guerra y de más progenitores que son en gloria (Sevilla: Francisco de Lira, 1634). [En adelante, Sermones fúnebres...]

4 La provincia de Andalucía se desgajó de la de Castilla en 1569 quedando conformada por los conventos ya fundados o por fundar al sur del río Guadiana. Estos eran, para las fechas que nos ocupan: Úbeda, Córdoba, Andújar, Jaén, Sevilla, Murcia, Badajoz, Tarifa, Marbella, Málaga, Almería, Baeza, Ronda, Coín, Granada, La Rambla, Jerez de la Frontera, y La Membrilla. Como se aprecia, dieciocho cenobios, de los cuales dos terceras partes, —y nos atrevemos a decir que los más importantes — están representados en el libro. Sobre los trinitarios de Andalucía, Ma Cruz García Torralbo, "El real monasterio de la Santísima Trinidad de Úbeda y su patrimonio en los siglos XVI Y XVII", Boletín del Instituto de Estudios Giennenses, 155 (1995): 61-160, 69. Para una primera aproximación a la orden y su evolución histórica puede servir de base, Juan Pujana, La Orden de la Santísima Trinidad (Trinitarios) (Salamanca: Secretariado Trinitario, 1993).

5 Sermones fúnebres... Dedicatoria al excelentísimo señor don Gaspar de Guzmán. 
Aunque no dudamos de que haya otros libros semejantes, es la primera vez que encontramos algo así, pues, como decíamos, no se trata una recopilación de sermones para formar un volumen con piezas de temática similar elaborado a posteriori, de las cuales tenemos varios y diferentes ejemplos ${ }^{6}$, sino que esta vez nos hallamos ante un conjunto de textos que coinciden exactamente en fecha, tema y congregación lo cual le da una unidad innegable y nos permite un análisis muy especial ya que podemos concluir que nos encontramos ante la visión que la orden trinitaria calzada de Andalucía quiso dar de sus patronos y, por ende, de su relación con los mismo. De aquí que sea fundamental detenernos en explicar las coordenadas temporales, espaciales y humanas de la publicación.

Empecemos por el autor, Luis de Córdoba Ronquillo, fraile trinitario, a quien los escritores de la orden sitúan, como en otros muchos casos, en la antesala de la santidad ${ }^{7}$. Sin embargo la realidad, como casi siempre, es algo más prosaica.

Muy poco es lo que sus biógrafos nos dicen de su ascendencia y origen ${ }^{8}$, no obstante podemos afirmar que procedía de una familia de estirpe conversa afincada en Granada y que, perteneciente a una mesocracia enriquecida, había

6 Quizá el más conocido sea Sermones funerales en las honras del Rey [...] Felipe II con el que se predicó en las de la Infanta D. Catalina duquesa de Saboya..., ed. por Juan Íñiguez de Lequerica (Madrid: Varez de Castro, 1599).

7 La primera aproximación al personaje la realizó Gil González Dávila, Teatro eclesiástico de la primitiva iglesia de las Indias Occidentales, vida de sus arzobispos y obispos y cosas memorables de sus sedes en lo que pertenece al reino del Perú (Madrid: Diego Díaz de la Carrera, 1655), t. II, 80v. De él beben gran parte de sus biógrafos posteriores dando una imagen bastante acrítica, edulcorada, escasa de fuente y alejada de la realidad, como el clásico de fray Antonio de la Asunción, Diccionario de escritores trinitarios de España y Portugal (Roma: Fernando Kleinbub, 1898), vol. I, 199-204 y 528 529. En esta obra se hace mención expresa a la aparición de su cuerpo incorrupto en 1674 y a sus dotes de adivinador del futuro cuando, al profesar en el convento de Úbeda "pronosticó todos los estados por que pasaría y dignidades que tendría, así dentro de la Religión como fuera",199. Poco más aportan Bonifacio Porres Alonso, "Luis de Córdoba Ronquillo", Diccionario biográfico de la Real Academia de la Historia (Madrid: RAH, 2003), http://dbe.rah.es/biografias/33774/luis-de-cordoba-y-ronquillo [última consulta 8 de enero de 2021] y Pedro Aliaga Asensio, "Los trinitarios y Felipe IV" en La corte de Felipe IV (1621-1665). Reconfiguración de la Monarquía Católica, dir. por José Martínez Millán y Manuel Rivero Rodríguez, (Madrid: Polifemo, 2017) t. III, vol. 3, 1723-1724. Nótese que todos los autores, excepto González Dávila, son compañeros de orden de nuestro protagonista.

8 Según Asunción, Diccionarios de escritores trinitarios ..., 529, el trinitario fray Domingo López había compuesto una vida de Córdoba Ronquillo "en 17 cuadernos", según informaba el 12 de Mayo de 1682 al padre Fr. José Rodríguez. Lamentablemente esta obra no parece que se publicase nunca ni sabemos de su existencia. Tampoco parece haberse publicado el manuscrito sobre la historia de la provincia de Andalucía de Trinitarios Calzados escrito por el mismo Domingo López y que se encuentra en el archivo de San Carlino alle Quattro Fontane en Roma. Cfr. M ${ }^{a}$ Cruz García Torralbo, "Las razones de un obispo: trinitarios versus dominicos", Boletín del Instituto de Estudios Giennenses, 160 (1996): 3749,38 . 
diseñado una estrategia de ascenso social en la que su imbricación en las instituciones de poder de la Monarquía eran una fase clave ${ }^{9}$. Fueron sus padres Luis Fernández de Córdoba y María Briceño Ronquillo, su segunda esposa. De él sabemos que descendía por vía paterna - su padre y abuelo, por tanto, de nuestro trinitario, fue Antonio de Córdoba - de una familia conversa procedente de Jaén, mientras que ella estaba emparentada por su rama femenina (su madre fue María de Molina) con los Fernández de Baena notorios confesos granadinos en pleno proceso de ascenso social a través de sus cargos municipales y riqueza plasmada en diferentes mayorazgos ${ }^{10}$.

Luis Fernández de Córdoba, había vivido en esta ciudad, en la que había sido jurado, hasta 1578 en que aparece avecindado en Granada donde contrae segundas nupcias con la referida María Briceño. Resulta curioso cómo, a pesar de ser el mayor de los hijos de Antonio de Córdoba y Teresa de Toledo, no heredó el mayorazgo sino que su padre decidió dejar a su segundogénito, Rodrigo López de Córdoba, el mayorazgo y el oficio de jurado por tener Luis "más posibilidades que su hermano"11, algo que debemos poner en relación con los cargos y negocios que tenía pues era administrador de rentas reales y jurado granadino.

Del matrimonio entre Luis y María nacieron varios hijos que se sumaron a los que había engendrado ya en su primera mujer, Mencía de Baeza (seis: tres hombres y tres mujeres). Todo parece indicar que para entonces Fernández de Córdoba había adquirido una importante posición en el mundo local granadino, posición que sus hijos mejoraron. Así, Diego Fernández de Córdoba Ronquillo, su primogénito, obtuvo una regiduría en Granada en 1616 pasando a formar parte de la oligarquía municipal con todo lo que ello conllevaba. De hecho esta rama familiar, maquillando sabiamente su linaje, conseguirá llegar a convertirse en nobleza titulada.

Volviendo a nuestro protagonista, Luis Ronquillo de Córdoba, fue el segundo hijo de este enlace y para finales de la segunda década del siglo XVII comenzaba a despuntar en la orden trinitaria andaluza, lo que permitiría a la familia ampliar sus aspiraciones de medro y progreso ya que, a través de la vía

9 Para la reconstrucción genealógica y comentarios que vertemos a continuación nos ha sido de gran utilidad Francisco Ildefonso Quevedo Sánchez, "Nobles judeoconversos: los oscuros orígenes del linaje Córdoba-Ronquillo", Sefarad, 76/2 (2016): 363-396, DOI: 10.3989/sefarad

10 Enrique Soria Mesa, "Los linajudos. Honor y conflicto social en la Granada del siglo de Oro" en Violencia y conflictividad en el universo barroco, ed. por Julián J. Lozano Navarro y Juan Luis Castellano, (Granada: Comares, 2010), 406-407.

11 Quevedo Sánchez, "Nobles judeoconversos...”, 390. 
eclesiástica se podía enlazar con la siempre gratificante influencia cortesana. Y en este contexto personal y familiar es donde debemos encuadrar la obra que estudiamos.

El padre Ronquillo había profesado en Úbeda en 1608 pero regresó a su ciudad natal para estudiar artes y teología, bagaje con el que fue elegido ministro del convento de Málaga ${ }^{12}$, y más adelante, provincial y visitador general, prior del convento de Santa Justa y Rufina de Sevilla ${ }^{13}$, de nuevo provincial para, finalmente, ser nombrado obispo de Cartagena de Indias ${ }^{14}$. Marchó para América en 1631 permaneciendo en Indias hasta finales de la década cuando regresó a la Península — sin permiso del Papa, al decir de sus biógrafos - ${ }^{15}$.Estando en su convento de Granada fue nombrado para la silla episcopal de Trujillo en el Perú, sede a la que nunca se incorporó pues murió en dicho convento el 16 de noviembre de 1640 .

Lograr un obispado en Indias, y más uno de la calidad del de Cartagena, no era una cuestión baladí. Y no se producía sin más. Era necesario contar con los apoyos suficientes en las instancias oportunas (valido, cámara, confesor...) para conseguir salir designado para tal prelacía pues, si bien conllevaba un viaje largo y muchas veces incierto, ofrecía unas posibilidades crematísticas de primerísimo orden si el pastor enviado desde la metrópoli pensaba más en su propio beneficio que en el de su grey. Forzoso es convenir, por tanto, que fray Luis de Córdoba supo hacerse bienquisto ante los responsables del patronato regio y logró un puesto que le elevaba muy por encima de lo que en un principio se podía esperar.

De esta forma, más allá de su labor pastoral — de la que no podemos dar cuenta aquí- lo que parece innegable a tenor del pleito que se desató sobre los bienes relictos tras su muerte y otras informaciones de época, es que fray Luis utilizó su posición para atesorar una importante fortuna que utilizó para

12 Estando en Málaga predicó un Sermón [...] en el Colegio de la Compañía de Jesús [...], en la octava de las fiestas que hizo a la canonización de [...] S. Ignacio y S. Francisco Javier, publicado por Juan Rene, 1622.

13 Sobre este convento, Pedro Aliaga Asensio, "La Orden de la Santísima Trinidad en Sevilla" en Órdenes y Congregaciones religiosas en Sevilla, coord. por Enrique Barrero González e Ismael Martínez Carretero, (Sevilla: Ateneo y Fundación Caja Sol, 2008), 273-290

14 El nombramiento para el obispado está fechado en Madrid el 8 de marzo de 1631. AGI, Contratación, leg. 5793, ff. .83-83v.

15 La real cédula ordenando le dejasen pasar a Indias acompañado de un compañero de orden, otro clérigo y seis criados se expidió en Madrid el 25 de abril de 1631 y la presentó en Sevilla el dos de junio por lo que debió hacer el viaje a finales de esa misma primavera. AGI, Contratación, leg. 5412,12. Regresó a España el 20 de diciembre de 1639. Aliaga Asensio, "Los trinitarios y Felipe IV”, 1724. 
beneficiar a su orden y, muy posiblemente, a sus allegados ${ }^{16}$. Oportunamente todo ello se fue olvidando y cuando en 1674 fue hallado su cuerpo incorrupto lo único que quedó para la posteridad fue la posible santidad del fraile. Suceso éste, el del casual desenterramiento, que llegaba en momento muy oportuno para afianzar el status social de una familia que ya había logrado hacer desaparecer todo ancestro incómodo. Pero para llegar aquí fray Luis tuvo que saber ubicarse en los diferentes espacios donde deseaba medrar.

Así, su ascenso en la orden coincidió con el momento de máximo esplendor de los trinitarios del reino de Castilla. Los decenios que cubren el final del reinado de Felipe III y los inicios del de Felipe IV fueron, posiblemente, los años de mayor influencia de esta congregación en la corte de la mano de dos de sus más destacados miembros: fray Simón de Rojas y fray Hortensio Félix Paravicino. El primero era considerado en la época como un verdadero santo y tenía acceso directo a los aposentos reales, favor que no desaprovechó para beneficiar a sus allegados ${ }^{17}$. Y aunque falleció el 29 de septiembre de 1624, su memoria estuvo muy presente en la corte durante varios años mantenida por proceso de beatificación en el que, entre otros, declararían el conde-duque y su esposa, así como su mayordomo Esteban Nieto de Villegas ${ }^{18}$.

El segundo se había convertido, a pesar de sus numerosos detractores (algunos de los más furibundos dentro de su propia orden) en un referente cultural de primerísimo orden y en una influencia clerical en palacio nada desdeñable ${ }^{19}$. Con ambos hermanos de hábito en Madrid, la orden trinitaria andaluza sabía que tenía grandes posibilidades de obtener apoyos y prebendas reales si sabía jugar

16 González Dávila, Teatro eclesiástico..., 80v., habla de que "A su rey le sirvió con diez mil pesos. Al convento de Sevilla le donó dos blandones de plata, fuentes, candeleros vinagreras y palabras; y otro tanto a los conventos de Granada, Málaga y Úbeda, menos lo blandones”. En el AGI hay copiosa documentación sobre los problemas sobrevenidos con su espolio y sus herederos y deudores. Véase también, Por don Alonso Suarez de Mendoza, y Doña Ana María de Córdoba Ronquillo su mujer..., (Madrid: Diego Díaz de la Carrera, 1645). BNE, Porcones, 823(24)

17 Sobre la vida de Simón de Rojas, puede manejarse Pedro Aliaga Asensio, San Simón de Rojas: Un santo en la Corte de Felipe III y Felipe IV, (Madrid: BAC, 2009) aunque el enfoque es claramente hagiográfico hasta cuando certifica el patronazgo que el clérigo ejerció y del que se beneficiaron, entre otras, sobrinos y sobrinas.

18 Para este proceso véase la tesis, lamentablemente no publicada, de $\mathrm{M}^{\mathrm{a}}$ Cruz de Carlos Varona, Imagen y santidad en la España Moderna (El ejemplo de los trinitarios calzados de Madrid), (Madrid: UAM, 2005), en especial la segunda parte.

19 Sobre Paravicino son de obligada referencia los trabajos de Francis Cerdán que citamos en la bibliografía. Para su contexto político, Fernando Negredo del Cerro, "Servir al rey y servirse del rey. Los predicadores regios en el primer tercio del siglo XVII" en Servir al rey en la Monarquía de los Austrias. Medios, fines y logros del servicio al soberano en los siglos XVI y XVII, ed. por Alicia Esteban Estríngana, (Madrid: Sílex, 2012), 379-382. 
sus cartas. Fue entonces cuando nuestro protagonista entró en escena aprovechando un acontecimiento extraordinario que le permitió contactar con el propio valido y presentarse - y presentar a su congregación - como una pieza más a colaborar para la mayor gloria de la casa de Olivares. Nos estamos refiriendo al viaje de Felipe IV a Andalucía ${ }^{20}$.

Este periplo, organizado por el conde-duque con diferentes objetivos políticos (vincular a las oligarquías andaluzas con el proyecto de don Gaspar, estrechar lazos entre la corte y la periferia, obtener financiación, acercar a Felipe IV a una parte de sus vasallos...) permitió a Córdoba Ronquillo establecer contacto con el valido.

Aunque no sabemos exactamente cómo llegó a ser recibido por Olivares y aquí no parece aventurado traer a colación la figura del citado Paravicino como intermediario pues, como es bien sabido, viajaba con la corte_-, si hacemos caso de sus palabras, se entrevistó al menos en dos ocasiones con el valido: una en Málaga y otra en Granada, y aprovechó para presentarle el sermón que había predicado en su capítulo provincial, celebrado en Andújar, a las exequias de don Enrique de Guzmán, padre de don Gaspar $^{21}$.

Desde luego el momento era el oportuno. Con la corte en Andalucía y el valido en plena campaña de autoafirmación, el que un instituto religioso se prestase a colaborar en la campaña de glorificación familiar ensalzando la casa de Olivares, que no dejaba de ser una rama menor de los Guzmán, era una ayuda muy bien recibida. En el caso que nos ocupa, además, era una forma de contrarrestar la poderosa influencia de los Medina Sidonia, rama principal del dicho linaje y grandes patronos eclesiásticos.

En este sentido, a finales de enero de 1624, justo antes de iniciar el viaje andaluz, el conde-duque había ganado un pleito contra sus primos, los referidos

20 El viaje comenzó el 8 de febrero y duró 69 días. Para el mismo resulta de imprescindible consulta Francisco Sánchez-Montes González, El viaje de Felipe IV a Andalucía en 1624. Tiempo de recursos y consolidación de lealtades, $1^{\mathrm{a}}$ ed. (Granada: Universidad de Granada, 2018).

21 “...y claro está que habiéndome V. Exc . en Málaga y Granada hecho tanta honra, cuando receloso de la pequeñez del don, llevé el sermón que prediqué en Andújar, en el capítulo provincial, y exequias también del Excelentísimo señor don Enrique de Guzmán, que ahora puedo seguramente prometerme la benignidad de V. Exc ${ }^{\text {a }}$, imitadora a la de Dios, que recibe mejor dones pequeños, si les acreditan ánimos crecidos". Sermones fúnebres... Dedicatoria al excelentísimo señor don Gaspar de Guzmán. El sermón que fray Luis predicó en Andújar no se encuentra en esta recopilación pero debe ser el que hemos localizado (pero no leído) en el centro teológico compostelano bajo el título: Sermón predicado en el convento de la Santísima Trinidad [...] de la ciudad de Andújar [...] en la celebración del capitulo provincial y fúnebres honras que la Provincia hizo al [...] Señor D. Enrique de Guzmán [...] Conde de Olivares..., (Murcia: Luis Liberòs, 1624). [Localizado en el catálogo del CCPB: http://catalogos.mecd.es/CCPB/cgi-ccpb/abnetopac/O12468/IDcb536914/NT1] 
Medina Sidonia, y en el mismo viaje había adquirido a la ciudad de Sevilla la jurisdicción de San Lúcar la Mayor, plataforma desde la que se conseguirá, ya en enero de 1625 , el ducado ${ }^{22}$.La estrategia de ensalzamiento, que se había visto premiada ya con la concesión de la grandeza, seguía en su línea ascendente para lo cual era importantísimo cubrir todos los flancos. Y la relación con las órdenes religiosas y el patronato de las mismas eran uno de ellos. Tengamos en cuenta que los patronatos sobre las Provincias y capítulos provinciales de las órdenes tuvieron un componente especial y elitista y que por ello estuvieron, casi siempre, en manos de las familias nobles más importantes y prestigiosas ${ }^{23}$. Rescatar, por tanto, el patronato que sus padres habían conformado - recordemos que don Enrique de Guzmán y Ribera había sido embajador en Roma y su esposa, María Pimentel de Fonseca era considerada por el Papa como la "santa condesa"24_ le permitía ampliar su capital simbólico acentuando la dimensión paternalista del poder nobiliario y asegurando unos servicios religiosos (sufragios, celebraciones por las almas de los antepasados...) tan valorados en la sociedad barroca. Aparecer, a ojos de la sociedad andaluza del momento, como patrono de la Santísima Trinidad implicaba reforzar lazos de fidelidad a la vez que contribuía al ensalzamiento público de su poder ${ }^{25}$.

Así pues, a un conde-duque preocupado por bruñir sus blasones se le ofrecía ahora la posibilidad de proclamar a los cuatro vientos la grandeza de sus ancestros. Porque era eso lo que fray Luis debió proponerle en las entrevistas que tuvieron en Málaga y Granada y con el aval de su predicación en Úbeda: que él era capaz de organizar que todos los conventos trinitarios de Andalucía predicasen con ocasión de la festividad de todos los santos unas exequias funerales por don Enrique - personaje que, por cierto, había fallecido en marzo de 1607y sus antecesores. Podemos por tanto colegir que el recién elegido provincial de la Santísima Trinidad, amparado por una figura como Paravicino, ofreció al hombre sobre el que descansaba el gobierno efectivo de la Monarquía un

22 Memoriales y cartas del Conde Duque de Olivares. Vol. I. Política interior 1621-1645, ed. por John H. Elliott, José F. de la Peña, y Fernando Negredo, (Madrid: Marcial Pons-CEEH, 2013), 145. Para la formación del patrimonio de la casa de Olivares, Antonio Herrera García, El estado de Olivares: origen, formación y desarrollo con los tres primeros condes (1535-1645), (Sevilla: Diputación de Sevilla, 1990).

23 Ángela Atienza López, "Nobleza y órdenes religiosas. Los patronatos sobre las Provincias y capítulos provinciales en la España Moderna" en Nobleza hispana, Nobleza cristiana: la Orden de San Juan, coord. por Manuel Rivero Rodríguez (Madrid: Polifemo, 2009), 2 vols., vol. 1, 553.

24 Gregorio Marañón, El conde-duque de Olivares. La pasión de mandar, 25 $5^{\mathrm{a}}$ ed. (Madrid: Espasa Calpe, 1992), 33-34.

25 Ángela Atienza López, "Patronatos nobiliarios sobre las órdenes religiosas en la España Moderna. Una introducción a su estudio" en Homenaje a Don Antonio Domínguez Ortiz, coord. por Juan Luis Castellano y Miguel Luis López-Guadalupe (Granada: Universidad de Granada-Junta de Andalucía, 2008), 3 vols. vol. I, 68-69. 
ejercicio de propaganda pocas veces practicado. De hecho, no nos consta que con anterioridad (y ya hacía más de quince años del deceso del segundo conde) se hubiera predicado nada al respecto en convento trinitario alguno ${ }^{26}$.

Es de suponer que Olivares aceptase de buen grado la oferta, lo que situaba a fray Luis de Córdoba en una posición envidiable para iniciar una colaboración con la corte que debía elevarle a cargos más importantes que el de mero provincial. Con estas aspiraciones entendemos cómo Ronquillo encargó a sus subordinados de todos los conventos trinitarios que trabajasen en un sermón panegírico para el padre de su patrón, que debería predicarse en noviembre y que lo preparasen para dar a la imprenta a la mayor brevedad posible. Y como hemos visto doce de ellos cumplieron con lo mandado, dando lugar a un libro con cierta divulgación y que, en varios repertorios bibliográficos, aparece como la única obra impresa de Córdoba Ronquillo, aunque sabemos que este trinitario dio a las prensas otros sermones en los años veinte, varios de ellos vinculados a la misma casa de Olivares $^{27}$.

Que la predicación fue un instrumento de propaganda pro-olivarista no parece admitir discusión tanto si atendemos al contenido de los sermones como al público que lo recibió. En todos los casos se hace mención a lo granado que fue el auditorio. Así en Sevilla asistieron el arzobispo, Luis Fernández de Córdoba Portocarrero, el asistente, Fernando Ramírez Fariñas (estrecho colaborador de Olivares) los marqueses de Alcalá, el conde de Palma, el marqués de Guadalcázar "con toda la demás nobleza de la ciudad". En Murcia hicieron lo propio el obispo y el corregidor, mientras que en Marbella escucharon la prédica todas las

26 Aunque sí se hicieron después. El mismo Córdoba Ronquillo predicó el 15 de diciembre del año siguiente un sermón de similar temática y que se imprimió bajo el título Sermón fúnebre que en misa de pontifical predicó [...] a las exequias de don Enrique de Guzmán, (Sevilla: Pedro Gómez de Pastrana,1625) y que se encuentra dedicado al conde-duque. En noviembre de 1626 repitió labor, pero esta vez recordando a la hija de don Gaspar, la marquesa de Eliche, recientemente fallecida y dedicando el sermón tanto a sus padres como al marqués de Medina de las Torres, su marido: Sermón fúnebre al aniversario y honras de la excelentísima Marquesa de Eliche, (Sevilla: s.e. 1626). Por último, tenemos constancia de que nuestro protagonista también predicó, asimismo en la ciudad hispalense de nuevo en 1627 un Sermón fúnebre que en el capítulo provincial de Sevilla en las horas del Exm. Sr. D. Enrique de Guzmán, Conde de Olivares, pero que no hemos podido hallar. Súmese a estas obras, Fray Gregorio Gálvez, Sermón fúnebre en las honras de los excelentísimos señores Condes Duques de Olivares, patronos que fueron de la Provincia del Andalucía, del Orden de la Ss. Trinidad de Redentores Calzados, (Málaga: Mateo López Hidalgo, 1658).

27 Félix Herrero Salgado, La oratoria sagrada en los siglos XVI y XVII. La predicación en la orden de la Santísima Trinidad. Predicadores mercedarios. Predicadores procesados por la Inquisición, (Madrid: FUE, 2006), 433, siguiendo a Nicolás Antonio, Bibliotheca Hispana Nova sive hispanorum scriptorum, (Madrid: viuda y herederos de Joaquín Ibarra, 1778) 2vols., T. II, 30 sólo referencia este trabajo. 
religiones, el corregidor de Ronda, la nobleza de la zona con los capitanes y gentes de armas, por poner tres ejemplos.

Aunque no podemos juzgar, como es obvio, el impacto del mensaje, sí que podemos constatar la intención. Y ésta iba más allá que la mera celebración de unas exequias por un patrón fallecido hacía más de una década y media. Lo que se buscaba, tanto en la oralidad como en la posterior impresión ${ }^{28}-\mathrm{y}$ que se imprimieran tantos sermones suponía un gasto que no sabemos quién sufragó, pero que debemos entender como inversión, bien para lo orden, bien para el patrono, en función de quien lo subvencionase - era situar a don Gaspar de Guzmán y Pimentel en el centro de un constructo ideológico que, mediante la sublimación de la memoria, hacía de la casa de Olivares una de las principales, sino la principal, del reino por sus altos valores nobiliarios y religiosos. Los progenitores del valido, remotos y cercanos, eran presentados, sin solución de continuidad, como los más fieles vasallos de sus reyes y de su Dios en un claro ejercicio de encontrar en el pasado las obligaciones tan necesarias en el presente (1624).No es ya que Lope Conchillos y su (para la época) manchado linaje desaparecieran, es que los trinitarios no tuvieron reparo en asegurar que sus patronos ostentaban la prelacía entre la propia casa de Guzmán, en un ataque, sin mencionarla, a la rama de Medina Sidonia. Cedamos por un momento la palabra al predicador cuando afirmaba que:

"El rey don Bermudo Segundo hizo merced del castillo de Toral al valentísimo y rico señor Nuño Fernández de Guzmán por haberle servido con un caballo en ocasión que peligraba su vida y aunque de esta Illma. familia de Guzmanes hay tantas y tan ricas casas, poderosas en grandeza, castillos y posesiones, la nuestra de Olivares entre todas campea, gozando de mayores posesiones y riquezas".

Y en esa línea los elogios se repiten, haciendo del linaje una garantía y legitimando, en cierta manera, el valimiento ya que alguien con tan preclara sangre y tan santos y fieles ancestros, malamente podría traicionar los valores sagrados del trono y el altar. Al asegurar que: "no solo ha sido esta nobilísima casa de Olivares desde su origen noble en sangre, sino también noble en virtudes y santidad, esmalte de la nobleza", no sólo se realizaba un panegírico del fallecido, sino que, sobre todo, se estaba sancionando la posición cortesana del valido. De

28 Quizá sea el momento de mencionar aquí que la difusión del patronato sobre la Trinidad andaluza no se circunscribió a la oratoria sagrada. Al respecto véase el grabado de Herrera el Viejo titulado La Trinidad adorada por las Santas Justa y Rufina, Felipe IV y la Reina y los Condes de Olivares, fechado en 1627, http://www.bibliotecavirtualdeandalucia.es/catalogo/es/consulta/registro.cmd?id=1014036 [Agradezco esta referencia a la profesora $\mathrm{M}^{\mathrm{a}}$ Cruz de Carlos Varona]. 
ahí que se hiciese especial hincapié en los méritos de su padre y abuelo como servidores de Felipe II y Carlos V, buscando en la historia familiar un antecedente que debía continuarse con Felipe $\mathrm{IV}^{29}$. Y los predicadores acababan concluyendo en ello. Cedamos para acabar de nuevo la palabra a Córdoba Ronquillo para entender cómo presentaba la figura de Olivares:

"Dejaron por suceso al excelentísimo señor conde de Olivares don Gaspar de Guzmán que hoy goza España y el mundo a cuya prudencia y afable fortaleza clamoraban (sic) los gobiernos de estos reinos hasta que la Majestad del rey nuestro señor Felipe IV le dio su favor y como en nuevo Atlante afianzó en sus hombros el mundo hallándose cuando príncipe y en la jornada de sus reales casamientos con la cristianísima infanta de Francia tan servido del conde que como gentilhombre de su cámara siempre le sirvió con amor y acompañó con lealtad que luego que coronó sus sienes la premió dándole su favor tan merecido" 30 .

Nuevo Atlante y favor merecido. Ese creo que es el mensaje que debemos retener.

\section{CONCLUSIONES}

En el escaso espacio concedido, hemos intentado pergeñar cómo una muestra de espiritualidad barroca - un ciclo de sermones funerarios - puede presentar otras lecturas alternativas no excluyentes. Profundizando en el autor y en las motivaciones, así como en el contexto político y de orden, se ha pretendido mostrar que la relación entre nobleza y órdenes religiosas ofrecía múltiples facetas que no deben encerrarse en un único marco explicativo. La celebración en noviembre de 1624 de las exequias por el alma de Enrique de Guzmán, segundo conde de Olivares, y sus progenitores no fue sólo un ejercicio de piedad y una muestra del saber hacer en los púlpitos de los trinitarios calzados andaluces. Se puede (y, creemos, se debe) interpretar también como un ejemplo que resalta la importancia que el clero poseía a la hora de legitimar situaciones políticas y sancionar posicionamientos sociales. Ambas opciones eran deseadas por el conde-duque quien desde el primer momento de su valimiento tuvo que hacer

29 No podemos glosar, por falta de espacio, los elogios a don Pedro y don Enrique de Guzmán, cfr. Sermones fünebres..., 31.

30 Sermones fúnebres..., 32. 
frente a una oposición eclesiástica que, con el tiempo, coadyuvaría a su caída ${ }^{31}$. De ahí su apoyo a una empresa que aportaría unos réditos en forma de capital simbólico nada desdeñables.

Y el reverso de la moneda la ofrece el ideólogo del proyecto. Un Luis de Córdoba Ronquillo que supo utilizar las oportunidades que la situación ofrecía para darse a conocer en el entorno del privado y, a fuerza de insistir en los elogios a la casa, lograr su promoción no sólo dentro de la orden, sino lo que es más importante, a un obispado en Indias.

Podemos hablar, por tanto, de que la predicación, una vez más, demuestra que poseía en la España de los Austrias unas potencialidades que trascendían la exégesis bíblica y el adoctrinamiento y la convertían en una herramienta fundamental en el horizonte cultural de nuestros antepasados.

\section{REFERENCIAS BIBLIOGRÁFICAS}

Aliaga Asensio, Pedro. "La Orden de la Santísima Trinidad en Sevilla". En Órdenes y Congregaciones religiosas en Sevilla, coordinado por Enrique Barrero González e Ismael Martínez Carretero, 273-290. Sevilla: Ateneo de Sevilla-Cajasol, 2008,

Aliaga Asensio, Pedro San Simón de Rojas: Un santo en la Corte de Felipe III y Felipe IV, Madrid: BAC, 2009.

Aliaga Asensio, Pedro, "Los trinitarios y Felipe IV". En La corte de Felipe IV (1621-1665). Reconfiguración de la Monarquía Católica, dirigido por José Martínez Millán y Manuel Rivero Rodríguez, t. III, vol. 3, 1723-1724. Madrid: Polifemo, 2017.

Asensi Pérez, Manuel. Crítica y sabotaje. Barcelona: Anthropos, 2011.

Asunción, Antonio de la. Diccionario de escritores trinitarios de España y Portugal, Roma: F. Kleinbub, 1898.

Atienza López, Ángela. "Patronatos nobiliarios sobre las órdenes religiosas en la España Moderna. Una introducción a su estudio" en Homenaje a Don Antonio Domínguez Ortiz, coordinado por Juan Luis Castellano y Miguel Luis López-Guadalupe, 3 vols. vol. I, 68-69. Granada: Universidad de Granada, 2008,

Atienza López, Ángela. "Nobleza y órdenes religiosas. Los patronatos sobre las Provincias y capítulos provinciales en la España Moderna". En Nobleza

31 Ha llamado la atención sobre este particular, Fernando Negredo del Cerro, "Deslealtades eclesiásticas en tiempos de Olivares. Algunas consideraciones sobre ejemplos precisos" Libros de la corte Monográfico 1 (2014) 186-213. Disponible en http://www.librosdelacorte.es/. 
hispana, Nobleza cristiana: la Orden de San Juan, coordinado por Manuel Rivero Rodríguez, 2 vols. vol. 1, 551-584. Madrid: Polifemo, 2009.

Atienza López, Ângela y José Luis Betrán Moya. "Religiosos y religiosas. Lazos e intereses de familia en el seno del clero regular en el mundo hispánico de la Edad Moderna”. En Familias en el Viejo y en el Nuevo Mundo, editado por Ofelia Rey Castelao y Pablo Cowen, 214-243. La Plata: Universidad de la Plata, 2017.

Cerdán, Francis. Paravicino y su familia, según el expediente C. 7720/1 del Palacio Real de Madrid y otros documentos, Toulouse: Hélios, 1994.

Cerdán, Francis. "Nuevos elemento. para la bio-bibliografía de Paravicino". Criticón 46 (1989): 109-124.

de Carlos Varona, $\mathrm{M}^{\mathrm{a}}$ Cruz. Imagen y santidad en la España Moderna (El ejemplo de los trinitarios calzados de Madrid), Madrid: Universidad Autónoma, 2005. [Tesis doctoral inédita]

Elliott, John H., José F. de la Peña y Fernando Negredo, eds., Memoriales y cartas del Conde Duque de Olivares. Vol. I. Politica interior 1621-1645, Madrid: Marcial Pons-CEEH, 2013.

García Torralbo, M ${ }^{a}$ Cruz. "El real monasterio de la Santísima Trinidad de Úbeda y su patrimonio en los siglos XVI Y XVII". Boletín del Instituto de Estudios Giennenses 155 (1995): 61-160.

García Torralbo, $\mathrm{M}^{\mathrm{a}}$ Cruz. "Las razones de un obispo: trinitarios versus dominicos", Boletín del Instituto de Estudios Giennenses 160 (1996): 37-49.

Herrera García, Antonio. El estado de Olivares: origen, formación y desarrollo con los tres primeros condes (1535-1645). Sevilla: Diputación Provincial, 1990.

Íñiguez de Lequerica, Juan, ed. Sermones funerales en las honras del Rey [...] Felipe II con el que se predicó en las de la Infanta D. Catalina duquesa de Saboya.... Madrid, Varez de Castro, 1599.

Marañón, Gregorio. El conde-duque de Olivares. La pasión de mandar, 25 ed. Madrid: Espasa Calpe, 1992.

Molina Recio, Raúl. "Iglesia y economía: la inversión nobiliaria en el mundo eclesiástico y su retorno económico. El ejemplo de los Fernández de Córdoba". En Poder, sociedad, religión y tolerancia en el mundo hispánico, de Fernando el Católico al siglo XVIII, editado por Eliseo Serrano Martín y Jesús Gascón Pérez, 1529-1547. Zaragoza: Instituto Fernando el Católico, 2018.

Negredo del Cerro, Fernando. "Servir al rey y servirse del rey. Los predicadores regios en el primer tercio del siglo XVII" en Servir al rey en la Monarquía de los Austrias. Medios, fines y logros del servicio al soberano en los siglos XVI y XVII, editado por Alicia Esteban Estríngana, 361-386, Madrid: Sílex, 2012. 
Negredo del Cerro, Fernando. "Deslealtades eclesiásticas en tiempos de Olivares. Algunas consideraciones sobre ejemplos precisos". Libros de la corte Monográfico 1 (2014): 186-213

Pujana, Juan. La Orden de la Santísima Trinidad (Trinitarios), Salamanca: Secretariado Trinitario, 1993.

Quevedo Sánchez, Francisco Ildefonso. "Nobles judeoconversos: los oscuros orígenes del linaje Córdoba-Ronquillo", Sefarad, 76/2 (2016) 363-396. DOI: $10.3989 /$ sefarad

Sánchez-Montes González, Francisco. El viaje de Felipe IV a Andalucía en 1624. Tiempo de recursos y consolidación de lealtades, $1^{\mathrm{a}}$ ed. Granada: Universidad de Granada, 2018.

Soria Mesa, Enrique. "Los linajudos. Honor y conflicto social en la Granada del siglo de Oro" en Violencia y conflictividad en el universo barroco, editado por Julián J. Lozano Navarro y Juan Luis Castellano, 401-427. Granada: Comares 2010.

Fernando Negredo del Cerro Instituto de Estudios Hispánicos en la Modernidad (IEHM)

Universitat de les Illes Balears Edificio Ramon Llull, Cra. de Valldemossa, km. 7.5 07122 Palma de Mallorca (España) https://orcid.org/0000-0001-6639-9649 